\title{
Propaganda y publicidad nazis en España durante la segunda guerra mundial: algunas características
}

\author{
Carlos Velasco Murviedro
}

\section{INTRODUCCIÓN}

A pesar del título de este trabajo, lo cierto es que el período exacto en que la propaganda nazi propiamente dicha se extendió en nuestro país fue mucho más concreto y menor en extensión: los casi tres años que van desde comienzos de 1941 hasta finales del 43; ambas fechas no son, a nada que se analice, fortuitas, ni mucho menos, pues la primera coincide con el auge y extensión militar de Alemania por Europa y parte de Africa, mientras que en el año 1943, si aún no está clara y definida la fecha de la derrota de los germanos, sí está ya echada la suerte de la guerra, y ésta no es desde luego favorable a éstos, por lo que el esfuerzo propagandístico devino cada vez más superfluo.

En el vaciado de periódicos y revistas españolas de la época se ha encontrado, al lado de la publicidad nacional, cuyos principales rasgos y notas ya hemos analizado en otros lugares (ver nota), un abundante material de este tipo creado, escrito y distribuido por algún organismo de propaganda nazi que, si en el caso español es ciertamente abundante y variado, hace pensar - por su numeración no necesariamente correlativa y el elevado número que alcanza, cercano al 500- en grupos semejantes de propaganda alemana dirigidos a otros paises ocupados por ellos, influidos por su ideología (caso del nuestro) o, por lo menos, neutrales y receptores por tanto de cualquier tipo de mensajes de los dos bloques en lucha.

(*) Véanse: “Sucedáneos de posguerra". Revista Historia $16 n^{\circ} 131$ (3. 1987), págs. 11 a 20 "Publicidad y Politica en la Guerra Civil». Revista Historia 16 n 143 (3. 1988), págs. 12 a 22; "Anuncios y posguerra". Revista Mensaje y Medios n 9 (12. 1989), págs. 83 a 91. 
Uno de los motivos por los que ha parecido conveniente estudiar esta información es por su indudable interés desde varios punto de vista: artístico, literario, técnico, propagandístico, geoestratégico, publicitario, político, económico, etc. Según se vayan comentando y analizando los anuncios de este tipo aquí incluídos, se verá con nitidez lo que hemos dicho, unas veces en el dibujo, otras en el tipo de ilustración, casi siempre en el texto cuidado y medido, frecuentemente en su contenido político claro y expansionista, etc.; en todo caso, y para el objeto de mayor interés de este trabajo, se insistirá en los aspectos técnicos, económicos y de exaltación germanista, intimamente ligados en esta aproximación al tema.

Así por ejemplo, y en el terreno político o en el económico -ciertamente delicados- se observan (al margen de la descalificación general que puedan merecer sus proyectos de dominación mundial) varios hechos: una elaboración cuidada, un mensaje y un texto calculados y pensados para tratar de convencer, una armonización inteligente entre lo gráfico y lo textual, una concepción «moderna» de la estructura del mensaje, etc. A lo largo de las páginas siguientes se verán ilustradas estas afirmaciones.

Los anuncios que se han podido analizar han sido agrupados en tres grandes bloques, según el tema genérico que les es común. En este primero - cronológicamente aparece también antes de los otros- se incluirá lo que podríamos llamar "propaganda alemana", toda vez que, aunque se trata de conectar en alguna medida con el continente europeo de un modo genérico, lo que busca directa y primordialmente es procurar convencer al lector de que todo lo alemán siempre es bueno y bien hecho (los grupos segundo y tercero no se van a tratar aquí y se comentarán al final, en los puntos 4 y 5 , de forma breve, siendo objeto de sendos estudios futuros pendientes de publicación).

Por último, una aclaración metodológica necesaria: aunque en términos exactos publicidad y propaganda son términos interrelacionados pero perfectamente diferenciados entre sí, su delimitación precisa requeriria, como en otros muchos campos, del concurso, el tiempo y la extensión que los estudiosos de los medios de comunicación dedican a este tipo de discusiones y aclaraciones. Sin embargo, para el objeto de nuestro estudio, mucho más modesto, nos bastará con apuntar la distinción entre ellos más usada comúnmente: la propaganda pretende convencer de (vender) una «idea" (política, moral, etc.), mientras que la publicidad trata de conseguir lo mismo con un «producto» (económico). En todo caso, hoy como ayer, la distinción no siempre es fácil de hacer con claridad, y la interdependencia de ambos términos abunda (la mezcla de lo ideológico con lo económico), siendo una buena muestra el caso que 
se presenta a continuación, y del que resulta bien expresiva la calculada ambigüedad del título del comienzo.

\section{EL «GENIO ALEMÁN»: ALGUNOS EJEMPLOS}

La serie de anuncios que a continuación se incluyen son un perfecto ejemplo de la propaganda bien entendida, que con sus esquemas centrales tan simples como efectivos (inventos de muchas cosas, fabricación de máquinas, artefactos complicados, puesta en marcha de complejas instalaciones, perfección y calidad de sus productos, etc.), favorecian la aceptación de esa idea tan extendida (como en gran parte válida) de que "lo alemán" es signo de garantía, calidad, fortaleza, acabado, perfección, etc., que prácticamente fue admitida por todos los países, y que aún dura en nuestros días.

\section{Los «Productos» fabricados en Alemania}

Un primer subgrupo de ellos (cuatro en total), se refieren en sus títulos a ciertos «Productos" alemanes. El primero (Anuncio A-103) se refiere a cómo "los colorantes alemanes triunfaron en los mercados del mundo sobre los colores naturales". Según ellos esto, más que un negocio, era concebido como "una especie de misión cultural», y al final del texto hacian unas reflexiones sobre los colores que, aunque buscando evidentemente "la venta" del producto, son todo un prodigio de sensibilidad y medida:

«El amor al color es dinamismo, tendencia positiva hacia las cosas. En lo sin color se manifiesta decadencia de los sentimientos...".

O también:

"Los colorantes de Alemania con su indeleble esplendor, unen a todos con la alegría que del color emana y que al color tiende".

Tanto en este anuncio como en el siguiente y en el último, se pueden observar en la parte gráfica dos grandes letras, una " $E$ " y una " $A$ " mayúsculas, encima de los mapas de dos países que son España y Alemania, respectivamente. El interés de tal observación radica en mostrar la obsesión por conectar ambas economías, aún de forma inconsciente 


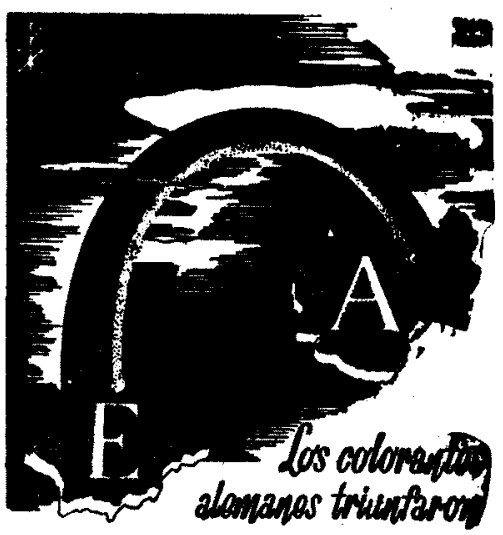

en les mercades def mundo sobse be colones an

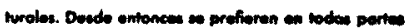

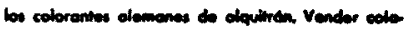

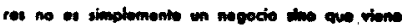

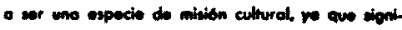

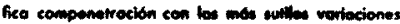

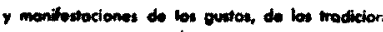
y del progreso do las nodionet. El emer of celo. do es dinonismo. tendeneid positive hodia los conoh En to in color 10 monifienta' decodendo de to

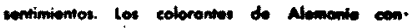
so indoloble esplender unen a todes con to aloorte

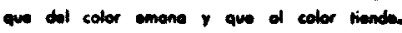

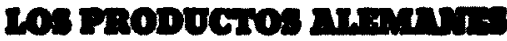

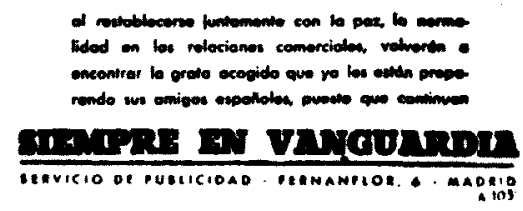

Anuncio $n{ }^{\circ}$ A-103

(Arriba, 29-1-1941, pág. 5)

(su máxima elaboración se podrá ver en un trabajo por publicar -comentado brevemente en los dos últimos párrafos de este trabajo, en el apartado 5-); en el caso anterior, por medio de un sencillo e ingenioso arco iris, y en el siguiente, por unos motores y unas máquinas que se supone vienen de aquel país al nuestro (Anuncio A-113), y no al revés, lógicamente.

Según éste, "los motores alemanes iniciaron la motorización del mundo", y hoy valen para todo, "tanto en tiempos de guerra como en tiempos de paz", y tanto para el transporte como para el "cultivo de la tierra"; en cualquier caso, y como se explicita bien claramente, el momento bélico destacaba con nitidez: 
"Las más grandes empresas guerreras que conoce la historia se realizaron con motores alemanes".

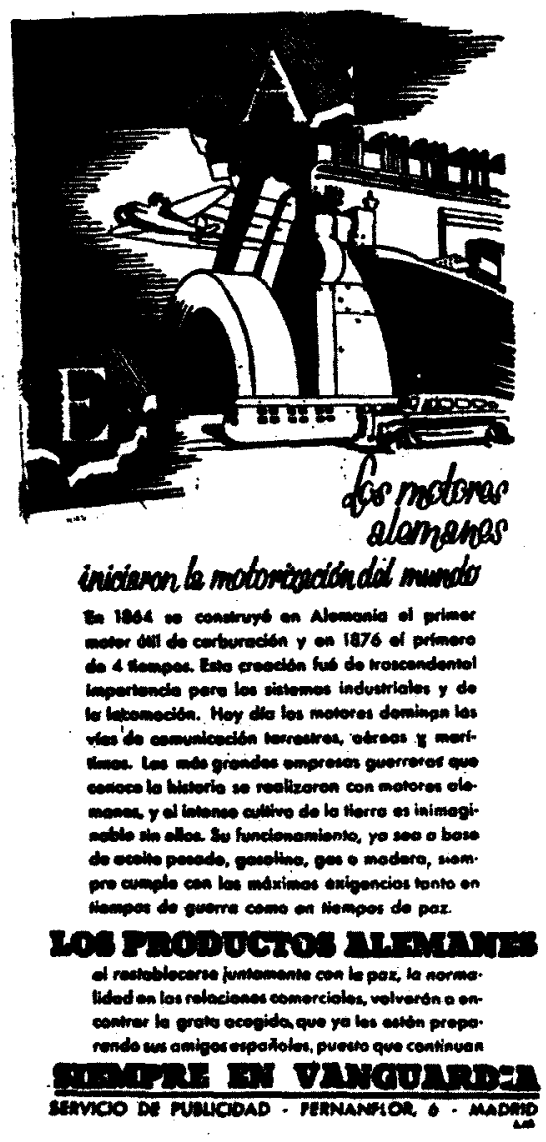

Anuncio A-113

(Arriba, 18-1-1941, pág. 3)

Por otra parte, hay que hacer notar que en la parte final de estos dos anuncios - y también en la de los dos próximos-, se repite una leyenda o slogan que merece ser comentado por tres motivos. En primer lugar, por su distanciamiento y cautela al hablar de la guerra, no dando por sentado una victoria del Eje que entonces sí parecía segura; y asi habla de que «al restablecerse juntamente con la paz, la normalidad en las relaciones comerciales...". En segundo lugar, el carácter de "siembra" de esta propaganda, al 
enfocarla no a corto, sino a medio y largo plazo, lo que queda claro cuando afirman que «LOS PRODUCTOS ALEMANES... volverán a encontrar la grata acogida al llegar la paz". Finalmente, no olvidan que a quien dirigen su propaganda es a un país ideológicamente afín, España; por eso, hablan de "la grata acogida que ya les están preparando sus amigos (sic) españoles».

En cuanto al siguiente Anuncio (no tiene ninguna numeración), es similar en su estructura a los anteriores, y se refiere concretamente a la cindustria eléctrica alemana", que es la "mayor exportadora del mundo" de este material, básico para toda clase de industrias, transporte, sanidad, comunicaciones, hogar. Al final, una frase revela de una forma un tanto indirecta la conveniencia de llevarse bien con Alemania, ya que «aún en tiempos de guerra", esta industria "ha demostrado su capacidad de atender las necesidades de sus vecinos y amigos (sic) europeos", frase parece que pensada para definir una situación de no beligerancia "amistosa" como la española.
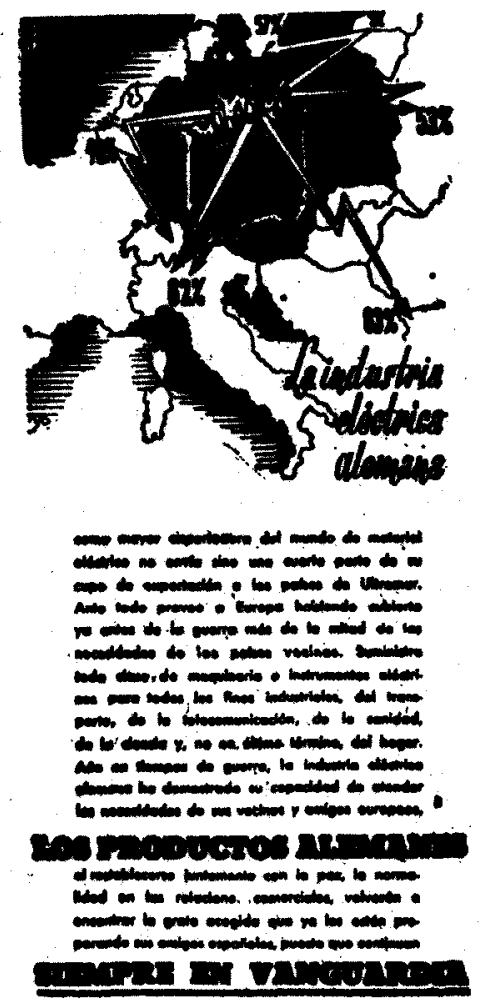

Anuncio A-

(Arriba, 14-2-1941, pág. 3) 
Finalmente, en el caso de "la industria óptica alemana» (Anuncio A119), y la "afamada casa Zeiss», se vuelve a enlazar España a Alemania, en este caso con artículos como gafas, cámaras de fotos, lentes, aparatos de precisión, fotocámaras, etc. que "conquistaron fama mundial» de la mano de la «proverbial exactitud alemana».

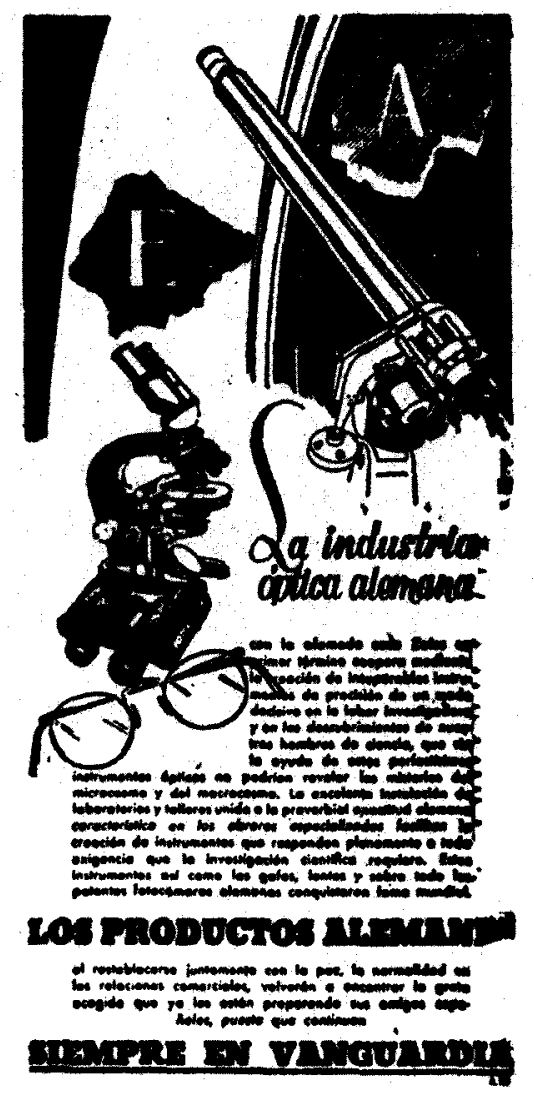

Anuncio A-119

(Arriba, 15-3-1941, pág. 3)

El «mayorismo» germánico (el caso del «mayorismo limitado»)

El subgrupo que sigue es más amplio (abarca ocho anuncios), y se refiere a lo que podríamos llamar el "mayorismo" alemán. Con él nos 
queremos referir a esa tendencia (fundamentada en algunos casos, pero forzada en los más) que intenta presentar lo hecho o fabricado por Alemania, en este caso, como lo "mayor» del mundo.

Este tipo de exposición, si no era falsa, tampoco era totalmente cierta, pues se basaba en la elección de unos colectivos tan restringidos a fuerza de limitarlos y calificarlos, que hacía relativamente fácil poseer luego el "mayor» de ellos. En el caso español, durante la época de Franco, esta forma de autobombo y alimentación del complejo de superioridad nacional también fue copiado, pero al hacerse con unas realizaciones mucho más modestas que en el caso alemán, dió lugar a unos resultados bastante más ridículos: nosotros decíamos que teníamos el edificio más alto del mundo, pero lo que no se decía es (o se decía por lo bajo), que era entre los que tenían estructura de cemento, y entre los construidos en medios de las ciudades, y entre los que se han hecho sólo para viviendas, y entre los que tienen planta cuadrada, y entre los que tienen los cimientos más profundos, y entre...; siempre puede encontrarse lo "mayor" de una cosa, si a costa de limitar, hacemos el colectivo a que pertenece cada vez más pequeño y particular.

Pues bien, en el caso que nos ocupa, se puede decir de los alemanes que fueron los creadores de este tipo de planteamientos tendentes a la superioridad, si bien su "mayorismo" se apoyaba en hechos reales, aunque "cualificados". El primer anuncio (Anuncio A-167), nos habla y explica asi cómo "la locomotora más (sic) rápida del mundo» es alemana, y alcanza los $200 \mathrm{~km} / \mathrm{h}$.

Al final de éste y de los otros siete anuncios, hay un par de temas que se van a repetir a modo de "coletilla»; el segundo no hace sino recoger un "slogan» que insiste en esta idea, en la de la perfección del producto germano:

"Insuperable siguen siendo las obras cumbres de la técnica alemana».

En el primero, por su parte, la banderola que contiene el texto enlaza con un grupo de anuncios que serán objeto de un trabajo posterior (y que se cita muy resumidamente en el apartado 4) de este trabajo, al final), y que trata de elaborar y construir un "gran espacio económico europeo" (sin Inglaterra ni Rusia, obsérvese el mapa). Por eso dice:

"El continente de posibilidades ilimitadas es hoy dia EUROPA: Para cumplir su nueva misión (!!) realiza las obras más trascendentales".

$Y$ volviendo al "mayorismo", en el siguiente ejemplo (Anuncio A-168) se habla de "la máquina de extracción mayor (sic) del mundo", que "se halla en Alemania occidental (sic, con minúscula, pues todavía no estaba dividida), construída por la AEG y DEMAG». 


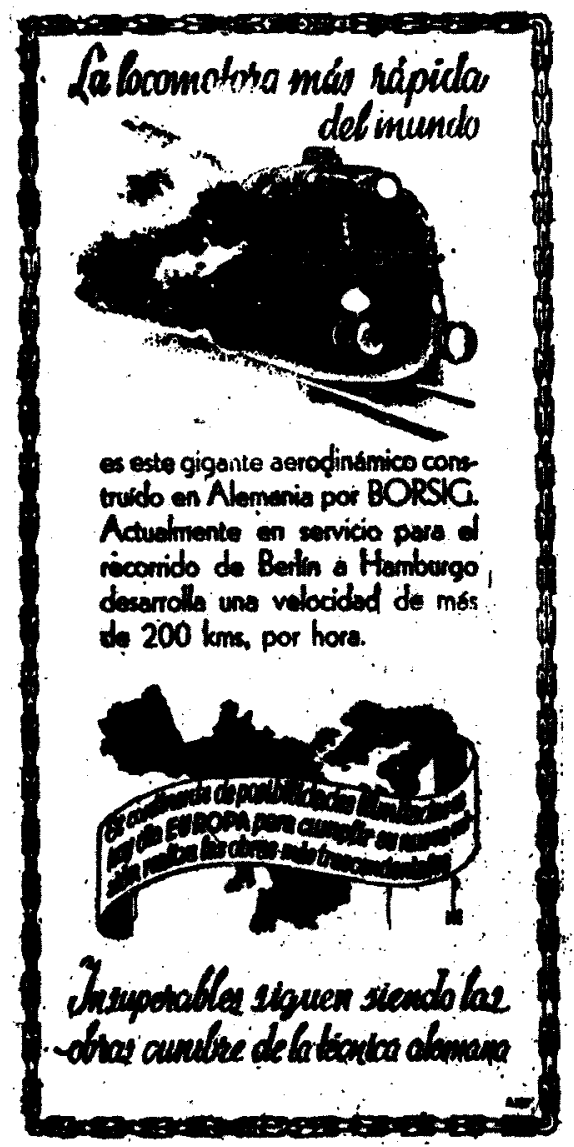

Anuncio A-167

(Arriba, 4-5-1941, pág. 3)

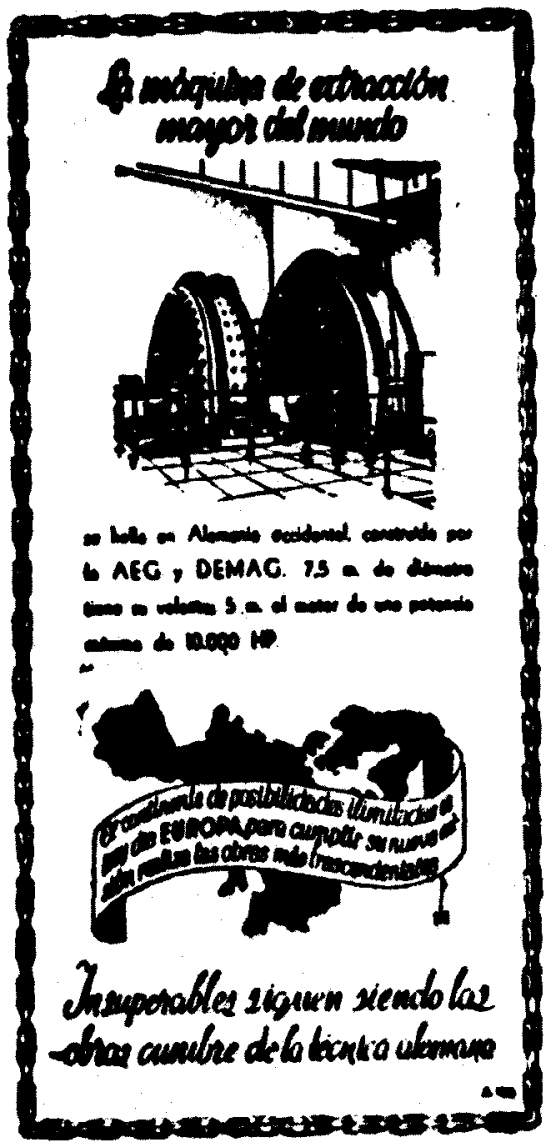

Anuncio A-168

(Arriba, 30-5-1941, pág. 2)

En el caso que va a continuación (Anuncio A-184), lo que se anuncia es la autoría alemana del "mayor (sic) buque Diesel-eléctrico del mundo".

Por su parte, en el caso siguiente (Anuncio A-210), el genio alemán es el responsable de "la mayor (sic) prensa de estrusión del mundo", de tipo hidráulico.

Después de estos cuatro primeros anuncios del "mayorismo", comienzan a aparecer otros que matizan dicho "mayorismo" generalizado, añadiendo una conjunción "para", que adjetiva y limita el relativo universalismo de la fase primera. Asi por ejemplo, el Anuncio A-231, que habla de la 


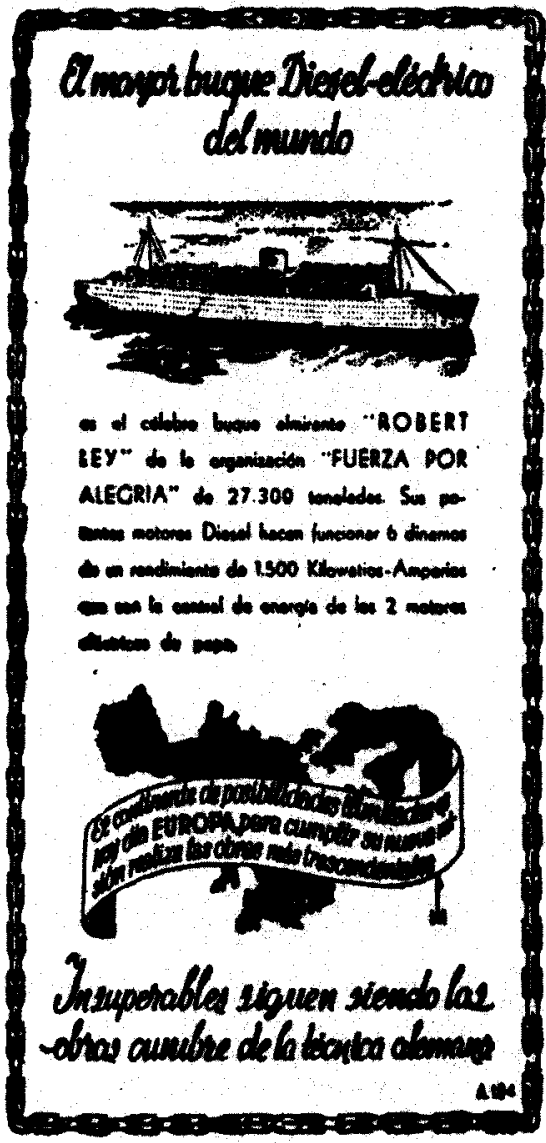

Anuncio A-184

(Arriba, 6-6-1941, pág. 3)

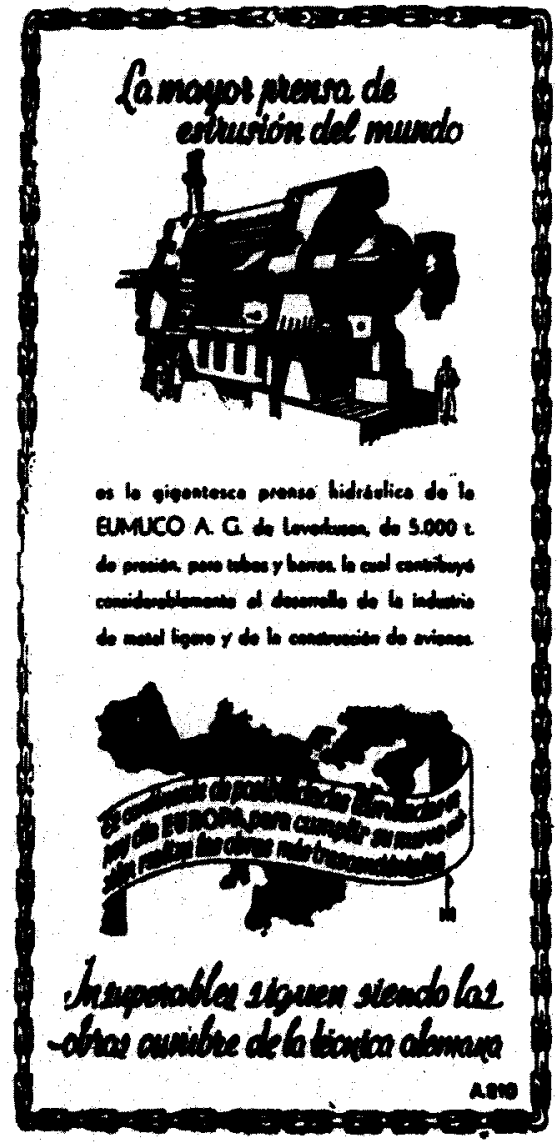

Anuncio A-210

(Arriba, 6-8-1941, pág. 3)

"mayor (sic) máquina del mundo», rebaja algo su ambicioso enunciado cuando se sabe que es "para (sic) curvar planchas de hierro para (sic) construcciones navales". A la vista de estos múltiples adjetivos y condiciones, se constata la treta ya comentada más atrás: disminuir el universo a considerar, para así resultar más fácil el hallazgo de una ventaja germánica en él.

El caso siguiente es también parecido (Anuncio $A-232$ ), ya que la "mayor (sic) prensa del mundo es para (sic) la fabricación de una resina artificial» que permita conseguir "piezas muy grandes» de ella. 


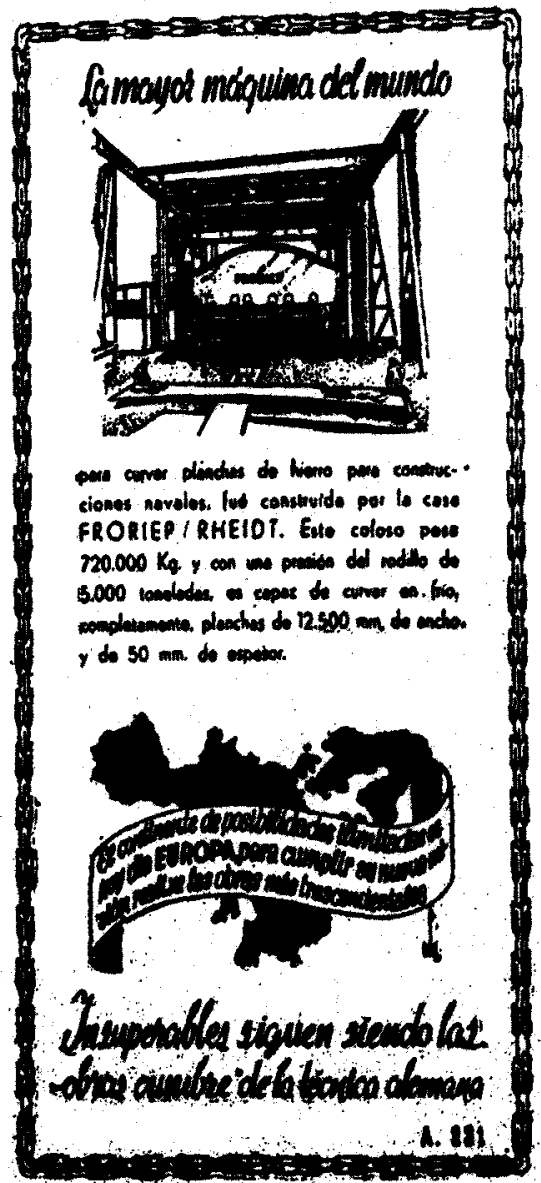

Anuncio A-231

(Vértice no 48, 9-1941)

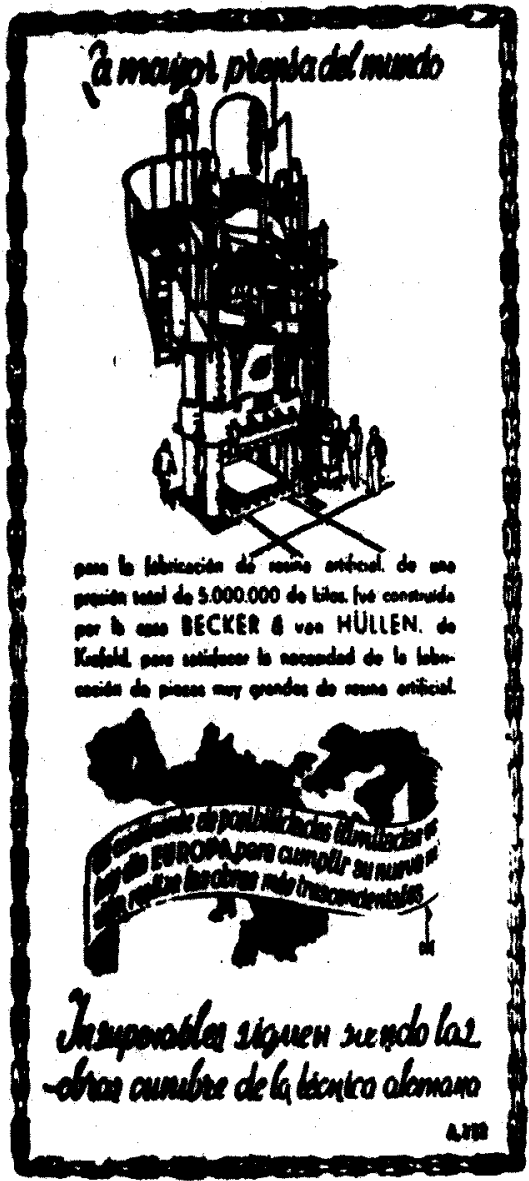

Anuncio A-232

(Arriba, 21-9-1941, pág. 4)

El contenido es muy similar en el Anuncio A-233, donde se dice que «la mayor (sic) instalación del mundo", es alemana, pero lo es "de (sic) destilación de hulla", y "para (sic) la fabricación de gasolina sintética».

Por último -en términos temporales-, el Anuncio A-235 vuelve al "mayorismo" sin limitaciones, que da fe de la germanidad del "mayor (sic) martinete del mundo", que "colocó en el fondo del mar postes de cemento armado de $40 \mathrm{~m}$. de largo y $1 \mathrm{~m}$. de diámetro". 


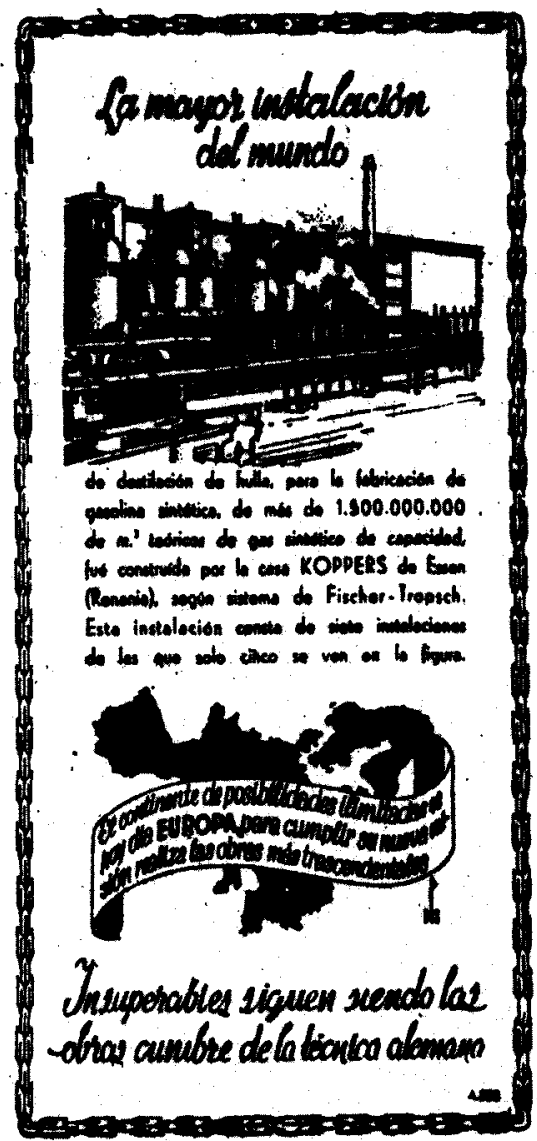

Anuncio A-233

(Arriba, 7-10-1941, pág. 5)

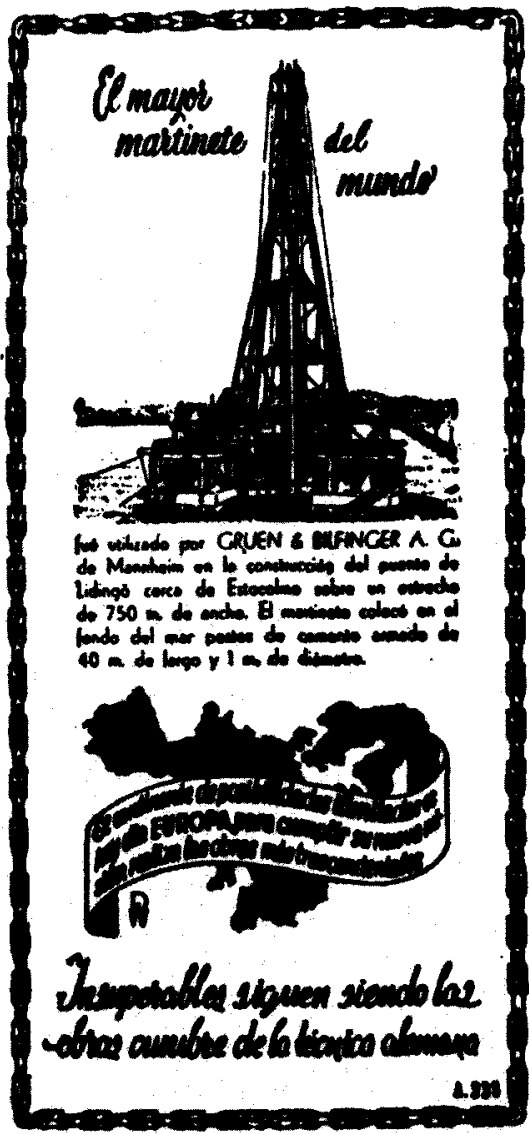

Anuncio $\mathrm{A}-235$

(Arriba, 9-11-1941, pág. 6)

\section{El «primerismo» alemán}

$Y$ pasamos ya a comentar y reproducir un tercer bloque de anuncios que, aún estando incluídos dentro del epígrafe referente a la inventiva, calidad y perfección del producto alemán, se diferencia notoriamente de los dos bloques anteriores, sobre todo por la idea central que los preside, y que en este caso podríamos llamar el "primerismo".

Como fácilmente puede colegir el lector, la explicación al término es muy similar a la del subgrupo anterior, cambiando, eso sí, el significado 
de la palabra que da nombre al vocablo. Dicho de otra forma, para conseguir el efecto deseado (presentar la importancia, mérito y rigor de la producción germana), se agruparán una seric de anuncios que bajo el lema "Una idea, una realización", tratarán de demostrar y explicar cómo el artículo alemán en cuestión es «el primero»: ya sea una máquina, un invento, un producto, etc., se nos dirá que fue creado, fabricado, ideado, o puesto en funcionamiento en primer lugar por alemanes.

Este es el caso, por ejemplo, del Anuncio A-304, donde se dice que hay que atribuir a Werner Siemens la "primer dinamo inventada", allá por 1866, con la que «proporcionaba al mundo el medio para engendrar corrientes eléctricas", favoreciendo así a todas las naciones: "De la realización de esta idea se beneficia hoy el mundo entero con la aplicación de la electricidad en todas las actividades humanas".

En cuanto al final de este grupo de anuncios, y como lema que se repetirá en todos los pertenencientes al título "Una idea, una realización", se puede observar cómo se incluye un mapa de Europa idéntico al del subgrupo anterior (el del "mayorismo»), con una leyenda que, aunque muy parecida, no es igual; su referencia al "gran espacio económico europeo" es ahora la que sigue:

"Europa, siendo el Continente de posibilidades ilimitadas fecunda las obras más trascendentales del mundo entero".

Por su parte, el Anuncio A-317 es semejante, y en él de lo que se habla es del "primer (sic) tranvía eléctrico del mundo", de 1887, que dió paso a los modernos de hoy (1942), que «aseguran la comodidad de los viajeros y la seguridad de su funcionamiento".

En cuanto al Anuncio A-318, el hallazgo es doble, pues no sólo fue alemán el "primer (sic) motor útil de carburación" (en 1864), sino que también lo fue "el primero (sic) de cuatro tiempos», en 1876. Los beneficios de ello fueron, lógicamente, múltiples, y para todo el mundo también:

"A la realización de esta idea se deben los grandes adelantos conseguidos en la locomoción, asi como demás industria... Tanto es asi que los motores dominan hoy dia las grandes vias de comunicación... para beneficio mundial».

El Anuncio A-334 que sigue es un tanto excepcional, pues aun dentro de esta tónica "primerista", lo que se anuncia no es algo en que Alemania 

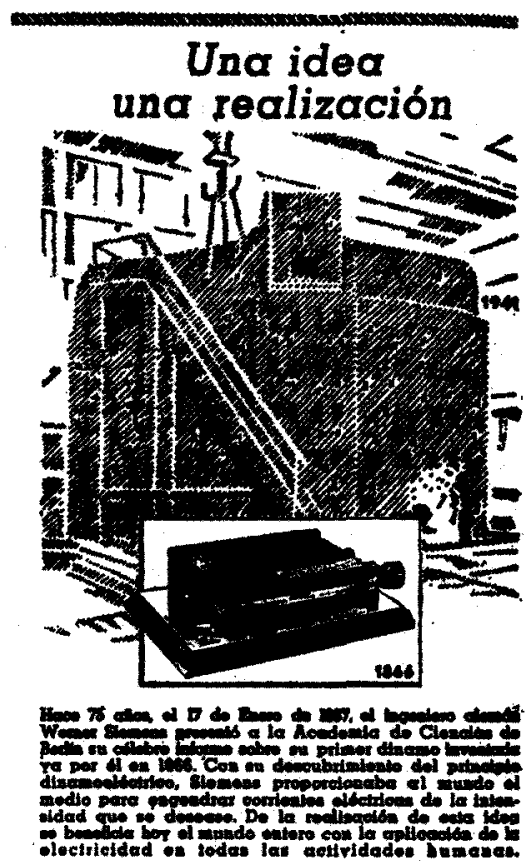

A- 304

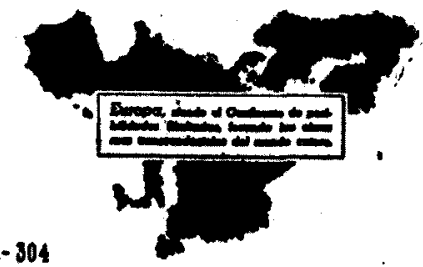

Anuncio A-304

(Arriba, 3-2-1942, pág. 2)

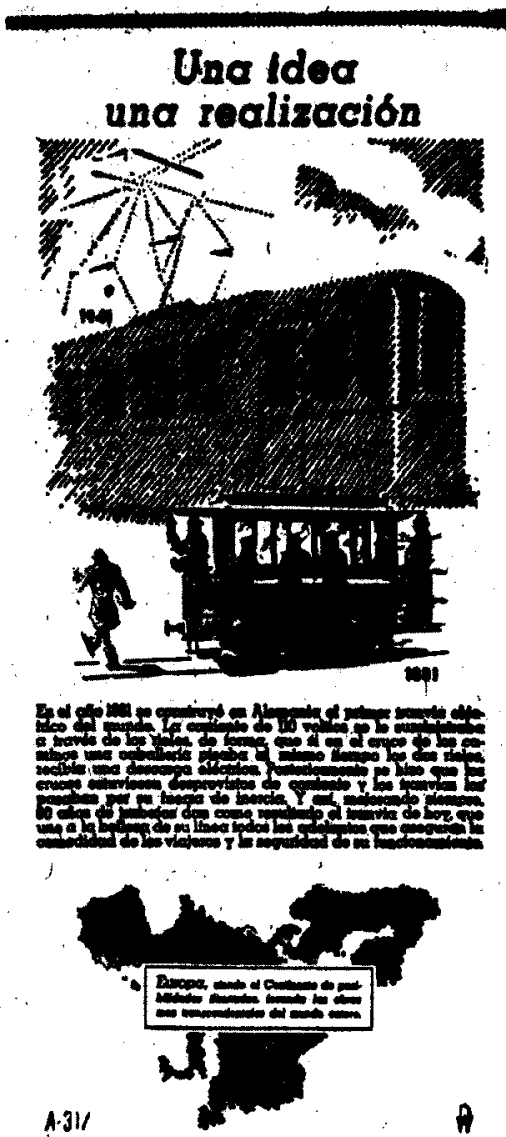

Anuncio $A-317$

(Arriba, 14-3-1942, pág. 5)

fuese la "primera», sino algo menor: Otto Lilienthal «es considerado como el precursor (sic) de la aviación», de modo que "la realización de sus ideas ha ayudado (sic) al perfeccionamiento en la construcción de aviones...".

$Y$ al lado del avión, no podía faltar tampoco el coche, del que el Anuncio A-336 dice que alemán fue «el primer (sic) automóvil con motor de petróleo y sus transmisiones necesarias", inventado por Daimler en 1889 y «hoy al alcance de una gran mayoria» (sic; se refiere a 1942).

Otro tipo de máquina inventada por germanos fue, en 1879 , la construcción de la «primera (sic) locomotora eléctrica del mundo» (Anuncio A- 


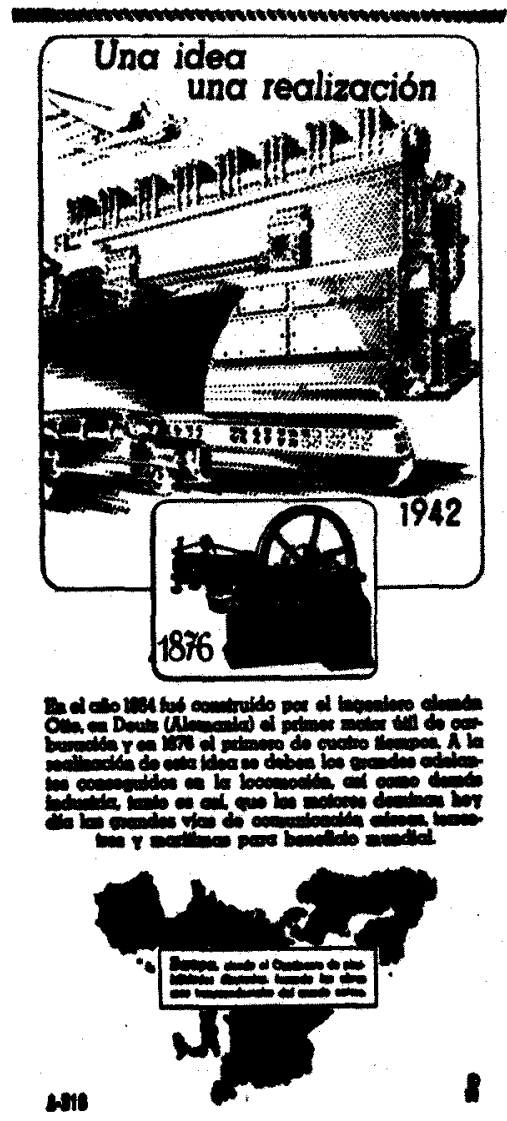

Anuncio A-318

(Arriba, 14-4-1942, pág. 2)

338), cuya foto resulta ciertamente pintoresca, hasta llegar a 1940, en que también lograron construir "la mayor (sic; véase un epígrafe anterior) locomotora eléctrica del mundo».

Por su parte, el anuncio siguiente, el $A-368$, presenta la noticia de que en 1897 lo que se construyó en Alemania fue el "primer (sic) MOTOR DIESEL del mundo en condiciones para el trabajo", el cual, al significar una "verdadera revolución de la técnica, regaló al mundo una fuente inagotable de energías».

Tampoco podía faltar en este repertorio la referencia a la invención tal vez más notable y conocida de la era moderna, la de la imprenta (Anuncio 


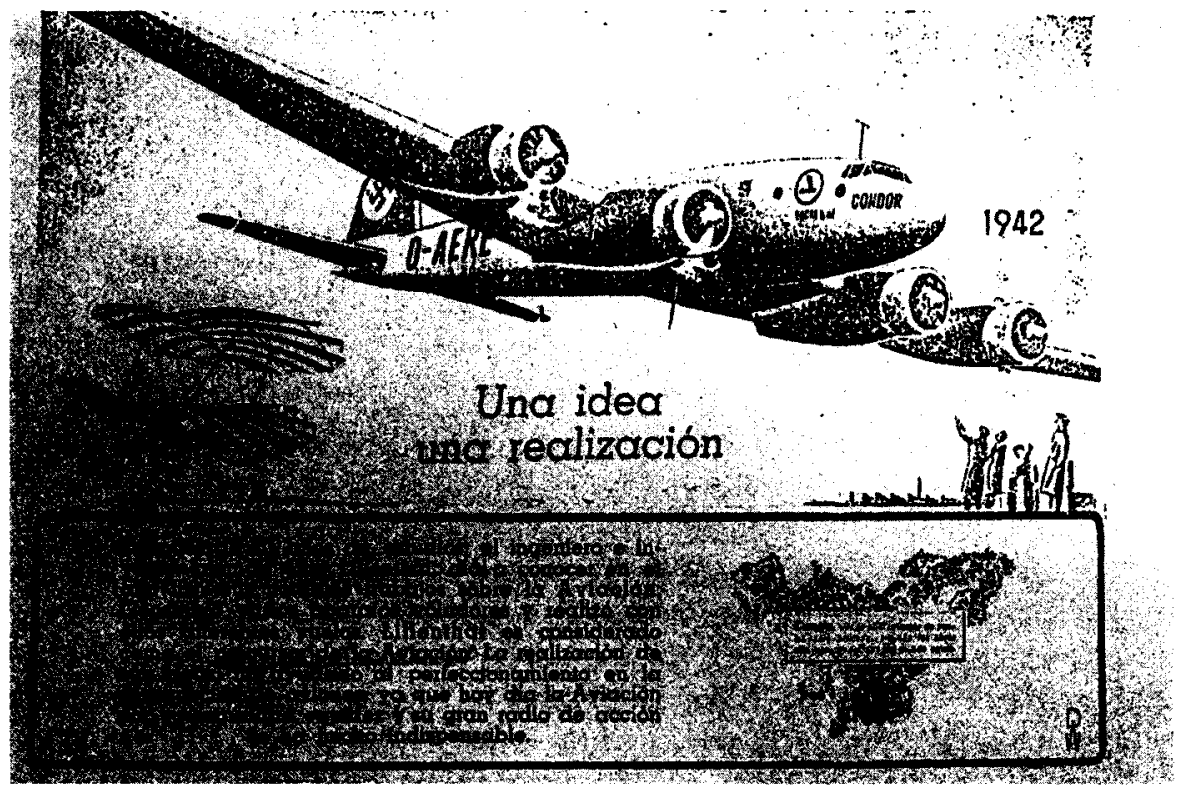

Anuncio A-334

(Vértice $\left.n .^{\circ} 55,4-1942\right)$

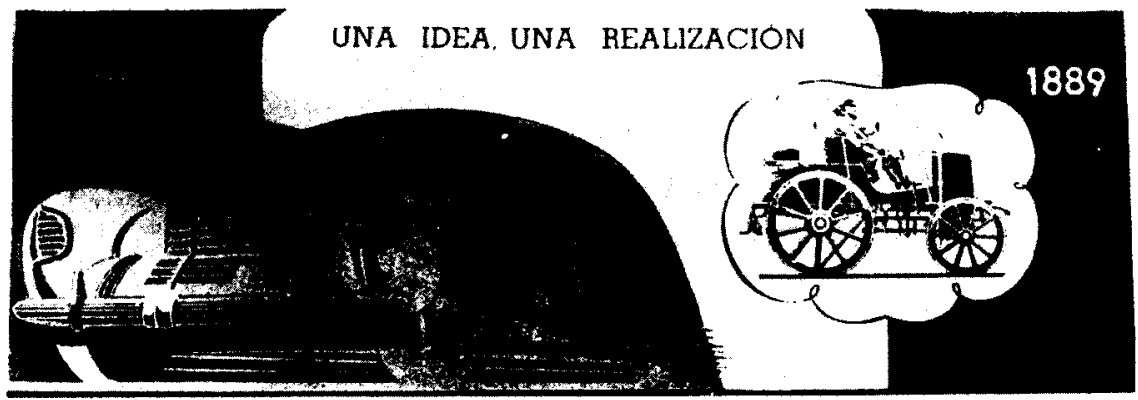

En el año 1889 fué construido el primer automóvil con motor de petróleo $\mathrm{Y}$ sus transmisiones necesarias, inventado por el mecánico alemán Teófilo Daimler, siendo notable esta fecha, pues de ella data la vulgarización de los motores de petróleo aplicados a los automóviles. A este gran invento se debe el máximo perfeccionamiento conseguido en la construcción de los automóviles contemporáneos, hoy al alcance de una gran mayoria, que puede disfrutar de eficientes servicios que comenzaron a desarrollarse en aquella fecha hasta llegar a su plenifud actual.

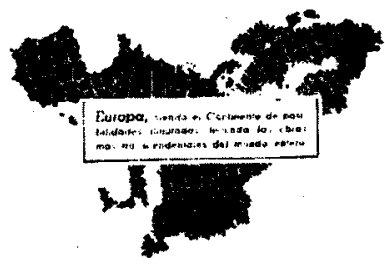




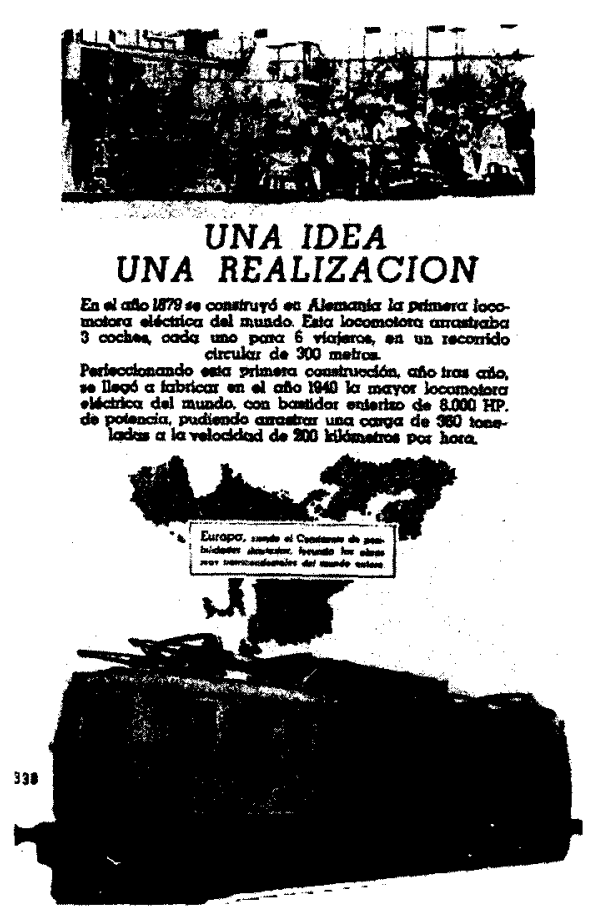

Anuncio A-338

(Vértice n. $\left.{ }^{\circ} 58,8-1942\right)$

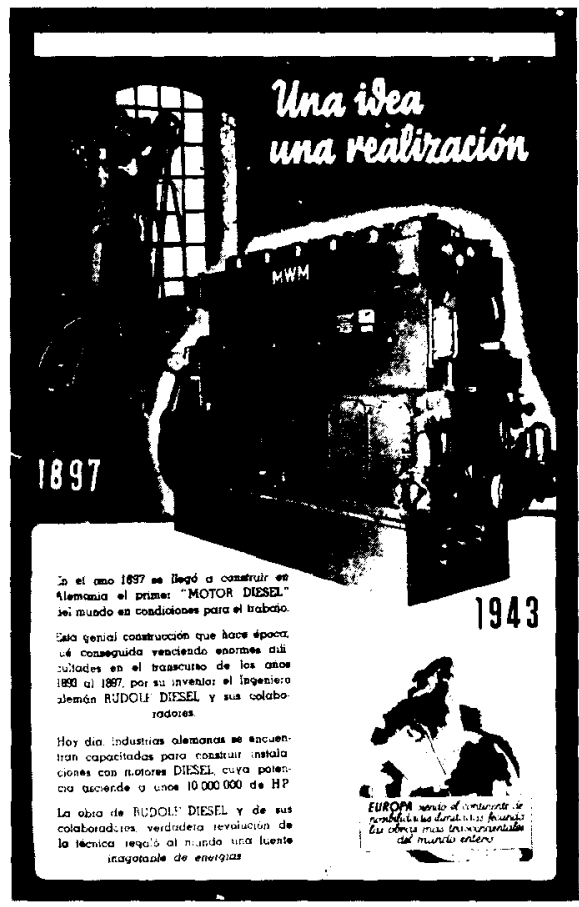

Anuncio A-368

(Mundo $n .^{\circ} 146,21-2-1942$ )

A-378). Como dice el texto, en 1440 Johannes Gutenberg imprimió «por primera (sic) vez en sus talleres libros mediante tipos sueltos".

Por último, el Anuncio A-390 habla de que en 1882 se fabricó en este país «la primera (sic) locomotora eléctrica para minas".

\section{CONCLUSIONES}

Hay ciertos aspectos de la breve exposición anterior que sobresalen a modo de resumen, algunos de los cuales, obviamente, necesitarian una mayor profundización (la cual ya está en marcha y verá la luz próximamente).

Como aspecto general que impregnaría todo el trabajo, conviene resaltar la mixtura conceptual entre lo propagandístico y lo publicitario: «ideas" y "productos" van de la mano en los anuncios nazis, mezclando el enfoque ideológico y económico en ellos, y ayudándose mutuamente a la hora de tratar de 


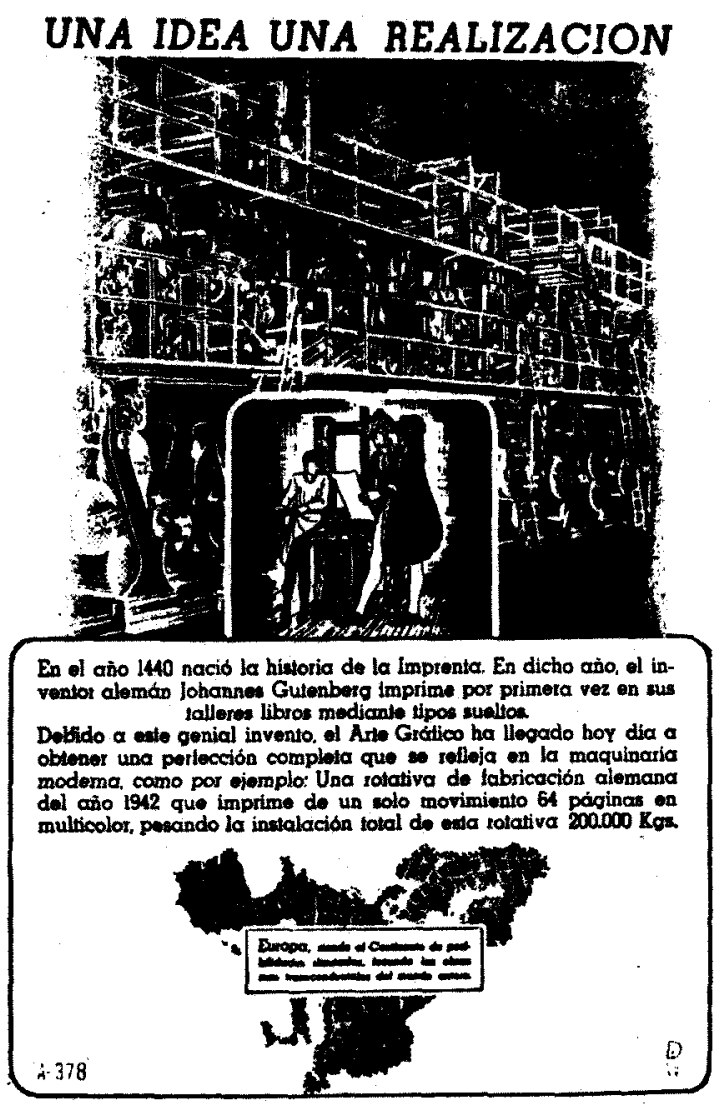

Anuncio A-378

(Mundo n. $\left.{ }^{\circ} 127,11-10-1942\right)$

convencer de unas ideas políticas determinadas (la bondad de una Europa unida - leáse dominada - bajo la hegemonía germánica), o de unos productos y técnicas concretas (los que eran fruto del genio alemán), todo ello mezclado para apoyar la «idea» global de la bondad de todo lo que fuera alemán.

1) En primer lugar, y en cuanto al apartado expuesto al comienzo, el de los «Productos" fabricados en Alemanía, contiene varias notas de interés:

- Por una parte, es la campaña propagandística históricamente más temprana, pues abarca anuncios publicados en el primer trimestre de 1941. 


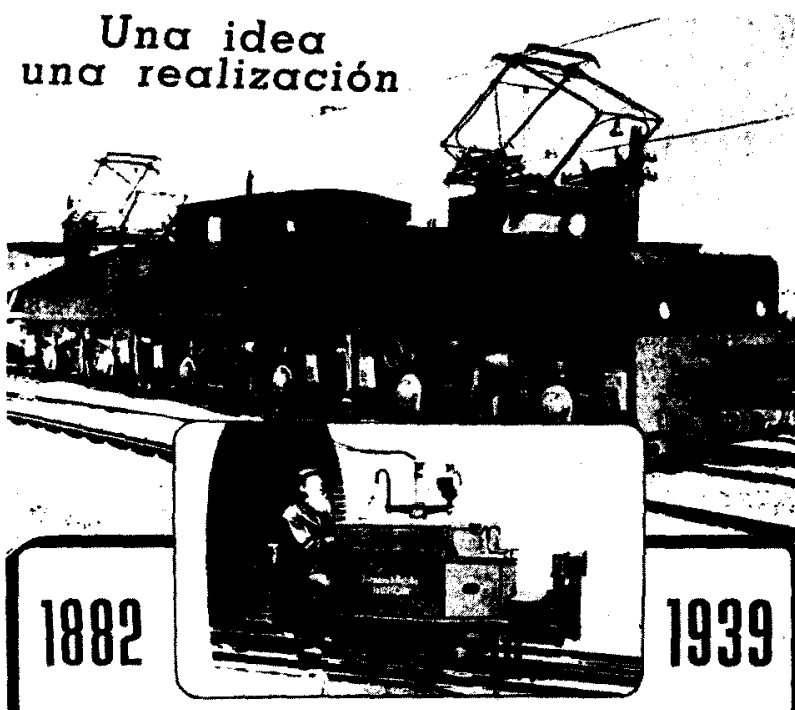

En el año 1882 se construyó en Alemania la primera locomotora eléctrica para minas.

Perteccionando esta primera construcción año tras año, llegó a fabricar en el año 1939 la locomotora olectrica de lego a labricar en descombro, mas pescada dol mundo, puss su peso noto cs

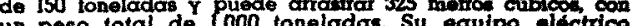
un peso total de 1.000 toneladas. Su equipo elforico.
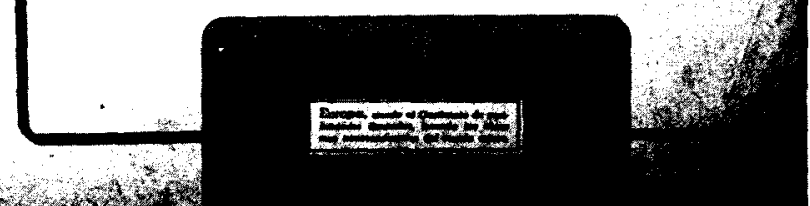

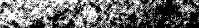

Anuncio A-390

(Mundo n. $\left.{ }^{\circ} 136,13-12-1942\right)$

- Por otro lado, y estéticamente hablando, el conjunto de estos trabajos es el más flojo y el menos elaborado (una letra " $P$ " y una " $X$ » o una " $\alpha$ " unidas es el distintivo de ellos, estando hecha la campaña por un "Servicio de Publicidad", en la calle Fernanflor no 4, de Madrid).

- A su vez, y en cuanto al mensaje, todos insisten en resaltar cómo «los productos alemanes" (sean cuales sean), están "siempre en vanguardia" entre los similares del resto del mundo, para lo que explican sus ventajas.

- En relación a España, este grupo de anuncios (menos uno) recoge siempre una alusión gráfica (mapas) y de contenido ("grata acogida... de 
sus amigos españoles»), acerca de las cordiales relaciones políticas entre nuestro país y Alemanía.

- Por último, y en cuanto a su difusión periodística en concreto, el medio utilizado fue siempre la prensa diaria (sobre todo el "Arriba"), por lo que parece fácil deducir una extensión amplia de ellos a grandes capas de población, a la vez que se observa la deficiente calidad del resultado impreso (por el papel).

2) En cuanto al segundo grupo de anuncios, el llamado por nosotros "Mayorismo" germánico, se puede subdividir a su vez en dos etapas diferenciadas con claridad:

\section{2.a) Mayorismo estricto:}

- Es el más absoluto (los cuatro primeros), y temporalmente es correlativo de la etapa anterior (la de los "Productos" alemanes), pues abarca desde mayo a noviembre de 1941. Su característica principal no precisa de mucha mayor aclaración: lo anunciado en cada caso hace de la máquina alemana en cuestión la "mayor» del mundo, sin ningún paliativo.

- Estéticamente se puede observar bastante similitud en la elaboración con el grupo anterior, aunque ahora aparece ya en todos una banderola con un texto, sobre un mapa de "Europa" (sin la URSS y Gran Bretaña), que mejora notablemente la presentación (Las siglas " $P$ » $y$ « $X$ » siguen apareciendo).

- Por lo que se refiere al mensaje, aunque continúa presentándose con claridad y de forma repetida la loa a lo producido en Alemania ("Insuperables siguen siendo las obras cumbre de la técnica alemana"), se incluyen por primera vez en todos ellos, encima del ya citado mapa del continente, un texto que aparentemente defiende una concepción europeísta:

«El continente de posibilidades ilimitadas es hoy día EUROPA (que) para cumplir su nueva misión realiza las obras más trascendentales".

De esta forma, la política real de tipo expansivo practicada por los nazis, se veía encubierta por un doble velo: el aparentemente "técnico" de la primacia de sus productos, y el pretendidamente "europeo" al defender una «EUROPA... de posibilidades ilimitadas, ... (con) una nueva misión» que (eso no se decía, aunque sí se llevaba a cabo) definía Alemania al dominar por las armas a casi todo el continente.

- Atendiendo a su difusión, estos anuncios salieron también en el diario "Arriba", siendo pues su calidad de impresión algo deficiente, y su prevista extensión al público, bastante amplia. 


\section{2.b) Mayorismo limitado:}

- Este segundo grupo (de otros cuatro anuncios), es algo coincidente en el tiempo con el anterior, pues aparece en la prensa entre septiembre y noviembre de 1941, es decir, al final del período del mayorismo absoluto. En cuanto a las siglas del dibujante o diseñador, en los tres primeros son iguales que las ya citadas, apareciendo en el cuarto unas mayúsculas nuevas entrelazadas: “D» $y$ « W».

- En términos estéticos, las consideraciones son idénticas a las ya descritas en el grupo precedente.

- En cuanto al contenido, puede decirse del mensaje también lo mismo que para el caso anterior, con una única salvedad: el ejemplo que se propone, aún hablando de que es el "mayor» del mundo en su género, le añade uno o varios adjetivos que, en definitiva, limitan grandemente su pretendida universalidad.

- Por último, y por lo que se refiere a la difusión, si bien tres de ellos siguen apareciendo en "Arriba", uno lo hace ya en "Vértice", revista mensual de alto nivel de calidad de impresión y de lectura en ambientes menos populares y más relacionados con la clase alta y cercanos al ámbito intelectual y cultural.

3) El tercer bloque analizado de anuncios lo hemos recogido bajo el epigrafe del "Primerismo", que hace referencia, obviamente, a la constatación de cómo ese artefacto, invento, máquina, etc., fue ideado primero por un alemán:

- En cuanto a la aparición temporal, esta serie es la de mayor duración, pues comenzó en febrero de 1942 y llegó hasta el mismo mes de 1943. El diseño de este grupo está ya todo él a cargo de las letras " $D$ » y «W» entrelazadas.

- Las consideraciones estéticas que merece este bloque son notablemente más favorable que todas las anteriores: aparece siempre una foto o dibujo del "primer» invento alemán de forma clara y nítida para, detrás de él, y en tamaño mayor, un dibujo difuminado en rayas o una foto bien clara recoge dicha aportación en el momento actual, acentuándose asi el contraste que marca la vertiginosa evolución de los distintos adelantos.

Asimismo, aparece el mapa europeo del caso anterior con la misma leyenda también referida a Europa.

- Por lo que se refiere al contenido, puede volverse a leer lo ya escrito en el apartado precedente, si bien en este caso debió considerarse 
oportuno hacer desaparecer la leyenda que se repetía al final de cada anuncio ( «Insuperables siguen siendo las obras cumbre de la técnica alemana"), quedando sólo la referencia, más presentable (por ser más neutra), referida a Europa.

- Sobre la difusión de este grupo de anuncios, se puede observar también con gran claridad una evolución, que afecta a la calidad del anuncio, la forma de hacerlo, el medio de prensa utilizado y, por tanto, la diferente cobertura de ellos según pasaban los meses.

- Febrero a abril de 1942 = Diario "Arriba", gran difusión, escasa calidad de impresión, y dibujo actual difuminado en rayas, para hacer el contraste.

- Abril a agosto de 1942 = Revista mensual "Vértice», gran difusión (pero bastante menor que la de "Arriba»), muy buena calidad de impresión (papel couché), y foto o dibujo del aparato moderno.

- Octubre de 1942 a febrero de 1943 = Revista semanal "Mundo", de gran difusión a nivel medio (a caballo entre el diario "Arriba» y la selectiva "Vértice"), con idénticas notas que las descritas para "Vértice".

4) Aunque la brevedad de este trabajo no permite recogerlos, existen otros dos bloques de anuncios de la publicidad nazi en España que revisten un enorme interés conceptual, propagandístico, ideológico, político y económico (y que serán objeto de un análisis pormenorizado en otras futuras investigaciones). Sus principales notas pueden, sin embargo, ayudarnos ahora a completar el panorama antes descrito.

El primer bloque de ellos era de contenido exclusivamente económico, y al lado de su gran belleza e impacto visual, que se podría englobar bajo el lema de "Europa y los Grandes Espacios Económicos" (GEE), se lanzan una serie de mensajes - relativamente breves en comparación con el resto de anuncios- que cantan y hacen ver lo positivo que habría de ser un "espacio económico" de ámbito europeo (dirigido, aunque eso tampoco se decía, por Alemania), que pretendía ser autárquico, creador de civilización y de adelantos técnicos y relacionado, eso sí, con otros «espacios económicos" que le complementarían en sus (supuestas) escasas deficiencias, como Africa y América Latina (pero que en realidad deberian estar a su servicio).

5) Hay un segundo grupo de anuncios nazis que, al menos desde el punto de vista de España, es el más interesante, pues si por una parte ejemplifican bastante bien lo que ellos entendian debía ser el papel de las diferentes economías nacionales dentro del "Gran Espacio Económico" europeo dirigido por el III Reich (la "especialización productiva"), por otra, 
al centrarse en las principales producciones de nuestro país en aquellos años (los "tópicos típicos": naranjas, minas, aceitunas, corcho y vino), ensalzaba su importancia en la distribución de papeles que a cada economía le era asignada, y que no era otro que el ya citado de "especializar" cada país y evitar la industrialización y futura competencia con el coloso germano de las naciones primordialmente agrarias.

Con ello se mostraba bien a las claras las consecuencias y objetivos de Alemania para con el resto de países: constituir "despensas" económicas de productos primarios y materias primas que, imprescindibles para el desenvolvimiento de la economía germana, no pudieran hacer sombra a sus productos industriales y, por tanto, debido a las relaciones de intercambio y a los precios relativos entre productos industriales y agrarios favorables a aquéllos-, se situasen en una relación de dependencia respecto a las naciones más industrializadas (léase Alemania, sobre todo). 